\title{
A Study of Using Picture Storybooks to Increase Chinese Vocabulary of Primary School Students
}

\author{
$\operatorname{Min} \mathrm{Li}^{*}$ \\ College of Chinese Language and Culture, Jinan University 510610, China
}

\begin{abstract}
It is an unsolved issue of how to increase the vocabulary of primary school students in Chinese reading in Singapore. According to the results from previous studies, one of the criteria of achieving independent reading is that students are able to read texts with at least $95 \%$ accuracy. The potential reasons for the current situation may be little exposure to Chinese reading after class, low reading interest and insufficient vocabulary. Therefore, in order to improve reading ability and read more, students first have to increase their Chinese vocabulary. Picture storybook is a combination of pictures and texts. The colorful pictures can not only attract students' attention, cultivate their reading interest, but also help them understand the words. In addition, the stories in the books provide students with vivid contexts. Teachers can use them to guide students to enhance vocabulary learning. This research was conducted with a class of Primary One (P1) students in Singapore. With the aim of increasing students' Chinese vocabulary, the researchers used picture storybooks as the learning materials for intervention. The study lasted for one year. This article first investigated current reading situation of P1 students and then explained the research methodology and design. It employed both qualitative and quantitative methods to assess students' performance on pre-and post- vocabulary tests, to conduct focus group discussion, to do classroom observation and to collect teacher's reflection after classes. The purpose of the study is to investigate the effectiveness of using picture storybooks to increase students' Chinese vocabulary and to motivate their reading interest.
\end{abstract}

Keywords: Chinese language education, picture storybooks, reading, vocabulary.

\section{THE RESEARCH BACKGROUND}

Based on a questionnaire of Chinese teachers in Singapore primary school found that there are lots of problems for students in learning Chinese language, the most outstanding is vocabulary. Statistics show that $68 \%$ of the teachers think that vocabulary teaching is one of the difficulties of reading comprehension teaching; $92.8 \%$ of the teachers think the biggest obstacle for students in reading is words. Songhao Liu (1999) argues that communication activities must rely on substantial master, and vocabulary as a whole, and it is more difficult to master than voice syntax, so vocabulary teaching should be in a central position in the reading, in order to help students to accumulate vocabulary. As is known to all, according to the bottom-up reading model, the words are in the first level [1]. If we can't understand the words, and will not be able to construct the meaning of the sentence; and can not construct the meaning of the sentence, it is impossible to understand the discourse. Therefore, to improve the students' vocabulary becomes a problem to be solved urgently in Chinese reading; it is the source of the research experiments.

At the time of design experiments, firstly, we are also considering the learning characteristics of students and the characteristics of Chinese reading in Singapore primary school (lack of suitable reading materials and reading). the age of the pupils of grade one is around seven years old, according to piaget's cognitive theory, the child of this phase to "the concrete operational stage ( 7 to 12 years old), children began to independent organization the right logic operation of a variety of methods (such as classification), but also inseparable from the specific things or with the help of the image." (ZhixianZhu, 2009 [2] [p.30].)

Language is an abstract symbol system, if we want to strengthen the effect of children's language learning, we should combine with the characteristics of children's cognitive development, and design the "image", "figurative" content into the process of language learning. Secondly, the academic of second language reading ability studies show that draw pictures and words in this mutual interpretation of the basic vocabulary play the positive role in improving students' reading and application as well as promote the development of students' cognition [3], Elley, for example, W.B. and Mangubhai, F. (1983) pointed out that use lots of interesting picture book (printed text is the target language), can make up for the second language and the language differences in cognition, can enhance learning motivation, and also can emphasizes the significance and the form, therefore, it is beneficial to the whole process of cognition. Thirdly, in the input of language learning, there is an important principle, the principle is comprehensible input. Stethen Krashen (1991) [4] thinks that comprehensible input in reading form can promote language acquisition. In the teaching design of experiment, therefore, we will use the picture story books and the students' known experience to help students understand the words and the content of the story, on this basis, 
further through language learning activities to strengthen the mastery and application of the words.

Given the above background and literature analysis, our research team designs one-year experiment by using picture books as a teaching medium.

\section{THE RESEARCH METHODS AND EXPERIMEN- TAL DESIGN}

\subsection{The Research Methods}

\subsubsection{The Research Question}

(1) Through the teaching of picture storybooks, whether can improve a student's vocabulary?

(2) Whether the teaching strategy of situation teaching and DR - TA (The Directed Reading - Thinking Activity) can help to improve a student's vocabulary?

(3) Picture storybooks teaching can improve the students' interest in reading?

\subsubsection{The Theory Basis}

The research topic from the actual investigation of teaching, it must rely on reliable theory to design experiment. Therefore, we adopted the theory from two aspects:

\subsubsection{Schema Theory}

Rumelhart, the artificial intelligence expert defines the schema as: A group of "support the knowledge structure of" or "constitute the cognitive construction sector" in the form of hierarchy is stored in long-term memory of people ( $\mathrm{Ru}$ melhart, 1980) [5]. That is to say, when meet new things, it will be understood only to put these new things associated with the existing schema, so the scheme is also known as cognitive framework. He and his colleagues Cook developed the schematic concept into a completed theory together; it used to study the psychological processes such as reading comprehension. In summary, the core content of schemata theory has two points: one is to use the old knowledge to understand learning new knowledge; second, the schema is organized knowledge structure.

\subsubsection{Link Memory}

"Peg word system has several kinds of forms, but the basic idea is that: learning a set of words as a link, to memory project is hung on the words that like a coat rack have many hooks, hat, tie and jacket can hang on." (Robert'L·sol, 2008) [6] [p. 212].

Based on Schema Theory and peg word system, we carried on specific design of teaching strategies and teaching framework. For example: selecting a scene from the story, the students based on the things in the scene pictures to remember words. It can also use this meaningful plot of the story as a "link" to tell the story again by learning to wear the individual words. In essence, a set of words to be effective organized and then built into the storyto form a whole or system. So that we can improve the efficiency of memory and enhance the memory effect. Schematic concept is the theory support from behind; the Link Memory is the explicit memory method.

\subsubsection{The Teaching Strategy: Situational Teaching}

Situational teaching method points to the teaching methods that, teachers purposefully introduce or create a specific scene with certain emotional color and image as the main body in the teaching process, in order to attract the student's attitude of certain experience, so as to help students understand the text, and the students' psychological function can be developed. The core of the situational teaching method is to stimulate students' emotion.

The biggest characteristic of picture storybooks is telling stories through the pictures, pictures can be vivid in many different situations, and our teaching activity is to design flexible according to the specific situation.

Example 1: according to the scene to memory (the scene of robbery) - from the picture storybooks "three robbers" [7]. First, the teacher can explain the scene about robbers robbed. Then asked the students in turn to speak out the name of things in the picture from left to right according to the order: the moon, the robber, axes, man, woman, dog. After students remember these six words, the teacher can be extended for application practice: let students to skewer the six words to tell a story according to the situation: "under the moon, there are three robbers, they with their axes in their hands. Man, woman dog is away."

The above example is a single learning of situation words. In the part of the teaching process of "repeat", our design is joined by "story", according to the story and string many situations together and then let the students say the story.

Example 2: according to the plot to link memories - from the picture storybooks "grandpa must be a way" [8]. After reading the story, let the students find out the cloth change in the story "tie fabrics- blankets- clothes-buttons-story". Let the students remember these six words, and say it. Then, let the students to join the sentence pattern into the story: "Put the cloth into the blanket, Blanket becomes old, made clothes by the old blanket, then clothes become old and then make it tie...".

The teaching design is to strengthen the students' longterm memory of words. "Perhaps the most compelling about long-term memory hypothesis is that: the information in the long-term memory organization in an orderly way." (Robert $\mathrm{L} \cdot$ sol, 2008) [9] [P166] this acknowledge is in line with the core point of the schema theory, in general, when knowledge into cognitive system of the human brain, organized arrangement Is conducive to memory and use. The picture storybooks' storyline and various circumstances specifically provide an "orderly organization".

\subsection{The Design of Experiment}

\subsubsection{The Research Object}

The object of study is a Chinese core class 2, grade 1; it is a class of neighborhood primary school in Singapore. An experimental class (25), a control class (27). Since then, the students have received eight weeks of teaching experiment, The week of school is 3 classes ( 90 minutes). 


\subsubsection{The Experimental Process}

$$
\begin{aligned}
& \ominus \text { Selected } 10 \text { intensive reading picture books } \\
& \ominus \text { Establish the corner of extracurricular reading } \\
& \circledast \text { Make students' read files } \\
& \text { (4) Teacher training (The strategy picture storybooks teaching) }
\end{aligned}
$$

Pre-test: students vocabulary test

$\ominus$ The design of lesson plan

$\ominus$ Classroom observation

Post-test:

$\ominus$ students vocabulary test

$\ominus$ Students focus interview (reading interest survey)

\subsubsection{Theprocess of Teaching and the Design of Teaching Plan}

The process of teaching is mainly divided into import activities, interactive reading and games after reading. Import activities mainly build reading atmosphere, and stimulate interesting, and it is also connected with students' life experience. Interactive reading can read with students, it can also let students play a role or tell a story (the teacher provides scaffolding words). The teacher should pay attention to the diversification of reading: take turns to read a story, read story together, read story on their own. The design of game part is priority to improve the vocabulary, the teacher can design tied to memory words, activities paste paper or paper stretchable latex. Focus on the vocabulary's learning, review and application. Xujing Qian (2003) [10], the expert of Chinese as a foreign language education thinks that accompanying words learning needs at least three phases: attention, speculation words according to the context and the support of words knowledge. Therefore, in the lesson plan, our design of the words learning activities run over and over again and it has administrative. In the teaching process as the guidance and principle, the team with the teachers designs the eight lesson plans of picture storybooks.

\subsubsection{Data Collection and Analysis}

(1) Data collection:

- Students' vocabulary test scores (pre-test+ post-test) (104)

- Classroom observation record (16)

- Teacher's reflection after classes (8)

- Students focus group discussion (6)

- The activities paper of students (216)

- The stories recording of Students (24)

(2) Data analysis (Table 1):

-The analysis of quantitative

The contrast of pre-and post- vocabulary tests score which experimental students participate in shows that both of experimental class and control class students' test scores have improved. The pre-test average score of the control class' students is 22.63 ( $\mathrm{SD}=3.64)$, the post-test average score is 27.48 ( $\mathrm{SD}=1.37)$, increased by 4.85 points; The pre-test average score of the experimental class students is $20.16(\mathrm{SD}=4.70)$, the post-test average score is 27.08 ( $\mathrm{SD}=$ 3.24 ), increased by 6.92 . The growth of the test average score of experimental class students is higher than control class students', To some extent, it shows that the teaching of picture storybooks improves the vocabulary test scores of experimental class.

\section{THE EXPERIMENTAL RESULTS AND DISCUS- SION}

\subsection{Qualitative Analysis}

To do classroom observation, to collect teacher's reflection after classes, to conduct focus group discussion, the pa-

\begin{tabular}{|c|c|c|c|c|}
\hline \multirow[b]{2}{*}{ Test Project } & \multicolumn{2}{|c|}{ The Control Class (29) } & \multicolumn{2}{|c|}{ Experimental Classes (26) } \\
\hline & Pre-Test Average Score & $\begin{array}{c}\text { Post-Test } \\
\text { Average Score }\end{array}$ & $\begin{array}{c}\text { Pre-Test } \\
\text { Average Score }\end{array}$ & Post-Test Average Score \\
\hline $\begin{array}{l}\text { Listen to the sound distin- } \\
\text { guishing words } \\
\text { (out of } 5 \text { points) }\end{array}$ & $\begin{array}{c}4.44 \\
(\mathrm{SD}=0.89)\end{array}$ & $\begin{array}{c}4.74 \\
(\mathrm{SD}=0.59)\end{array}$ & $\begin{array}{c}3.52 \\
(\mathrm{SD}=1.30)\end{array}$ & $\begin{array}{c}4.60 \\
(\mathrm{SD}=0.71)\end{array}$ \\
\hline $\begin{array}{l}\text { The word circle diagram } \\
\text { (full score } 15 \text { points) }\end{array}$ & $\begin{array}{c}12.63 \\
(\mathrm{SD}=1.39)\end{array}$ & $\begin{array}{c}13.70 \\
(\mathrm{SD}=0.95)\end{array}$ & $\begin{array}{c}11.64 \\
(\mathrm{SD}=2.34)\end{array}$ & $\begin{array}{c}14.04 \\
(\mathrm{SD}=1.31)\end{array}$ \\
\hline $\begin{array}{l}\text { Words fill } \\
\text { (out of ten) }\end{array}$ & $\begin{array}{c}5.56 \\
(\mathrm{SD}=2.62)\end{array}$ & $\begin{array}{c}9.04 \\
(\mathrm{SD}=0.94)\end{array}$ & $\begin{array}{c}5.00 \\
(\mathrm{SD}=2.31)\end{array}$ & $\begin{array}{c}8.44 \\
(\mathrm{SD}=1.81)\end{array}$ \\
\hline $\begin{array}{l}\text { Total score } \\
\text { (out of } 30)\end{array}$ & $\begin{array}{c}22.63 \\
(\mathrm{SD}=3.64)\end{array}$ & $\begin{array}{c}27.48 \\
(\mathrm{SD}=1.37)\end{array}$ & $\begin{array}{c}20.16 \\
(\mathrm{SD}=4.70)\end{array}$ & $\begin{array}{c}27.08 \\
(\mathrm{SD}=3.24)\end{array}$ \\
\hline
\end{tabular}
per of students' activities, the recordings of students tell a story.

Table 1. The data analysis of students' vocabulary pre-test and post-test scores. 


\subsubsection{Students}

Through the analysis of activities of paper, we can see every class they learned many words. Because in the process of teaching, it is important to design the learning activity of words, the teacher through different activities to strengthen the words learning, finally, assessing the effect of students' words learning in the classroom through the activities of paper. As a result, the quality of the students' paper reflect students' mastery of words whether in the classroom or after class activities completed. Through to the individual student tracking contrast, we also found that along with the advancement of picture storybooks reading class, the paper of students' activities has more and more vocabulary.

Through focus group discussion, we can understand their reading interest greatly strengthened. Reading interest is the important power of stimulating the students to continue reading, so we must pay attention to it. Relative to the reading skills, it is a more fundamental driving factor. Especially for children, "interest is the bait... we're going to pass significance to children, if the method is not lively and interesting, it can't attract his attention, and that it is a good meaning is not in his head." (GuangcaiHao, 2009) [11].

\subsubsection{Teachers}

Through the observation and analysis of teacher reflection form, the team found that the most outstanding performance of teachers is in the following aspects: 1 , teaching aims are becoming more and more clear and specific; 2, designing activities according to aims in the teaching link, that is to say, vocabulary as the teaching aim completely implementation in the process of teaching; 3 , the design of students' group activities task is more and more appropriate, in terms of the control of difficulty degree is better and better; 4 , the familiarity of teachers to the teaching plans is higher and higher, and they can improve the part of design flexibility, so as to combine the students' practical language ability and to better achieve the teaching goal.

\section{CONCLUSION}

Through the quantitative and qualitative analysis, we can see clearly: the vocabulary teaching through picture story book scan effectively extend the Singapore elementary student's vocabulary; it can also improve their reading interest. In the process of the whole classroom teaching, students can use the picture storybooks to understand and memory words, they can also memory more words by using link memory. At the same time, etc., can apply learned words, the highest aim of language teaching, at the same time, the highest state of words understanding is that through the rich class activities: playing a role or telling a story, students can use the words of they have learned, and then push the words learning to the level of application.

Needless to say, there are some disadvantages and problems in the research of the experiment: for example, the promotion of students' extracurricular reading quantity is limited; the audio output of students who tell a story is not a lot. All of these inspire us to further thinking and try our best to be more mature in the future study.

\section{CONFLICT OF INTEREST}

The authors confirm that this article content has no conflict of interest.

\section{ACKNOWLEDGEMENTS}

Declared none.

\section{REFERENCES}

[1] S. Liu, "Reading class vocabulary training," Chinese language teaching in the world, no.4, 1999.

[2] Z. Zhu, "Thechildren's psychology," Beijing: people's education press, 2009.

[3] W. B. Elley, and F. Mangubhai, "The impact of reading on second language learning," Reading Research Quarterly, vol. 19, no.1, 1983.

[4] S. Krashen, "The Input Hypothesis: An Update. Georgetown University round Table on Language and Lingistics," Linguistics and Language Pedagogy: the State of the Art, 1991.

[5] D.E. Rumelhart, "Theoretical Issues in Reading Comprehension," .Hill-sadle, NJ: Lawerce Erlbaum Associates, 1980.

[6] R.L. Sol, "Cognitive psychology," Shanghai: Shanghai people's publishing house, 2008.

[7] T. Ungerer, "Three robbers," Zhang Jianming. Jinan: tomorrow publishing house, 2009.

[8] P. Gilman. "Grandpa must be a way," Song Pei. Jinan: tomorrow publishing house, 2013.

[9] R.L.Sol, "Cognitive psychology," Shanghai: Shanghai people's publishing house, 2008.

[10] X. Qian, "The research of the accompanying vocabulary learning in Chinese reading," Journal of Peking University (philosophy and social sciences edition), no.4, 2003.

[11] G. Hao, "The picture storybooks is how good," 21 st century publishing house, 2009.

\footnotetext{
Received: June 10, 2015

Revised: July 29, 2015

Accepted: August 15, 2015

(C) Min Li; Licensee Bentham Open.

This is an open access article licensed under the terms of the (https://creativecommons.org/licenses/by/4.0/legalcode), which permits unrestricted, noncommercial use, distribution and reproduction in any medium, provided the work is properly cited.
} 